\title{
Neuropathology of Cervical Dystonia
}

\author{
C.N. Prudente ${ }^{1}$, C.A. Pardo ${ }^{2}$, J. Xiao ${ }^{3}$, J. Hanfelt ${ }^{4}$, E.J. Hess ${ }^{5}$, M.S. LeDoux ${ }^{6}$, and H.A. \\ Jinnah ${ }^{7}$ \\ 1 Dept. of Neurology, Emory University, Atlanta GA - cpruden@emory.edu \\ 2 Dept. of Neurology \& Neuropathology, Johns Hopkins University, Baltimore MD - \\ cpardov1@jhmi.edu \\ ${ }^{3}$ Dept. of Neurology, University of Tennessee Health Science Center, Memphis TN - \\ jxiao@uthsc.edu \\ ${ }^{4}$ Dept. of Biostatistics \& Bioinformatics, Emory University, Atlanta GA - jhanfel@emory.edu \\ ${ }^{5}$ Dept. of Pharmacology \& Neurology, Emory University, Atlanta GA - ehess@pharm.emory.edu \\ ${ }^{6}$ Dept. of Neurology, University of Tennessee Health Science Center, Memphis TN - \\ mledoux@uthsc.edu \\ 7 Dept. of Neurology, Human Genetics \& Pediatrics, Emory University, Atlanta GA
}

\section{Abstract}

The aim of this study was to search for neuropathological changes in postmortem brain tissue of individuals with cervical dystonia (CD). Multiple regions of formalin-preserved brains were collected from patients with CD and controls and examined with an extensive battery of histopathological stains in a two-stage study design. In stage one, $4 \mathrm{CD}$ brains underwent a broad screening neuropathological examination. In stage two, these $4 \mathrm{CD}$ brains were combined with 2 additional $\mathrm{CD}$ brains, and the subjective findings were quantified and compared to 16 agematched controls. The initial subjective neuropathological assessment revealed only two regions with relatively consistent changes. The substantia nigra had frequent ubiquitin-positive intranuclear inclusions known as Marinesco bodies. Additionally, the cerebellum showed patchy loss of Purkinje cells, areas of focal gliosis and torpedo bodies. Other brain regions showed minor or inconsistent changes. In the second stage of the analysis, quantitative studies failed to reveal significant differences in the numbers of Marinesco bodies in CD versus controls, but confirmed a significantly lower Purkinje cell density in CD. Molecular investigations revealed 4 of the CD cases and 2 controls to harbor sequence variants in non-coding regions of THAP1, and these cases had lower Purkinje cell densities regardless of whether they had CD. The findings suggest that subtle neuropathological changes such as lower Purkinje cell density may be found in primary CD when relevant brain regions are investigated with appropriate methods.

\section{Keywords}

spasmodic torticollis; autopsy study; Marinesco bodies; THAP1; DYT6

(C) 2012 Elsevier Inc. All rights reserved.

Corresponding author H. A. Jinnah, M.D., Ph.D. 6300 Woodruff Memorial Research Building 101 Woodruff Circle Department of Neurology Emory University Atlanta, GA 30322 Phone: 404.727.9107 Fax: 404.712.8576 hjinnah@emory.edu.

Publisher's Disclaimer: This is a PDF file of an unedited manuscript that has been accepted for publication. As a service to our customers we are providing this early version of the manuscript. The manuscript will undergo copyediting, typesetting, and review of the resulting proof before it is published in its final citable form. Please note that during the production process errors may be discovered which could affect the content, and all legal disclaimers that apply to the journal pertain. 


\section{Introduction}

Dystonia is a disorder characterized by sustained or intermittent involuntary muscle contractions leading to twisting movements and abnormal postures (Tarsy and Simon, 2006). The most frequent manifestation is regional involvement of isolated muscle groups, with the neck as the most commonly affected area (Defazio, 2010). People with cervical dystonia (CD, or torticollis) suffer from over-activity of neck muscles with involuntary turning, tilting, or twisting of the head. A cause is not identifiable in most cases, where the disorder is known as primary or isolated CD. In contrast, a cause is identifiable in secondary or acquired $\mathrm{CD}$ and may include medications, trauma, space-occupying lesions, and developmental or degenerative conditions. Although $\mathrm{CD}$ is the most common primary dystonia, conclusive evidence implicating specific regions of the nervous system is lacking (Hedreen et al., 1988; McGeer and McGeer, 1988; Standaert, 2011). A review of the literature disclosed only 15 reports, and no consistent neuropathological changes were noted (Table 1). The failure to detect overt changes has contributed to belief that there are no neuropathological defects in primary $\mathrm{CD}$.

On the other hand, imaging techniques consistently reveal abnormalities in primary CD (Neychev et al., 2011; Zoons et al., 2011). Positron emission tomography has revealed abnormal activity of the cerebral cortex, basal ganglia, cerebellum, and thalamus. Voxelbased morphometry has shown abnormal white and gray matter volumes in the cerebral cortex, basal ganglia, cerebellum and thalamus. Diffusion tensor magnetic resonance imaging (MRI) also has suggested the existence of microstructural anomalies in white matter tracts within the prefrontal cortex, basal ganglia, thalamus and corpus callosum. Studies of secondary CD also have pointed to the cerebellum, brainstem and basal ganglia (LeDoux and Brady, 2003). These imaging studies raise the possibility that subtle anatomical defects may occur within specific brain regions.

Results from animal studies have further pointed to specific regions where anatomical abnormalities might be expected. Multiple studies in different species have implicated both the basal ganglia and cerebellum in different types of dystonia (Breakefield et al., 2008; Neychev et al., 2011). Animal models of potential relevance to cervical dystonia have more specifically implicated the interstitial nucleus of Cajal (INC), red nucleus, and nearby regions (Carpenter et al., 1958; Malouin and Bedard, 1982; Fukushima, 1987; Walker et al., 1990; Klier et al., 2002; Neychev et al., 2011). The human imaging studies, combined with results from animal studies, provide clues for locations where neuropathological changes might be expected in patients with primary $\mathrm{CD}$. The purpose of the present study was to use recent imaging and animal studies as a guide to delineate potential neuropathological changes in primary $\mathrm{CD}$.

\section{Materials and Methods}

\section{Autopsy material}

The National Institute of Child Health and Development (NICHD) Brain and Tissue Bank for Developmental Disorders at the University of Maryland was searched for autopsy specimens of subjects with CD. Twenty cases of possible primary CD were reviewed with approval by the Institutional Review Board of the Johns Hopkins University. Among these, 14 had histories compatible with primary CD according to current criteria, but only 4 had sufficient tissue of good quality for study (CD1-4). Tissue from 2 additional cases (CD5 and CD6) became available after the initial screening study and was included in the second part of the study. Because these samples came from a public brain bank, systematic sampling of multiple regions for stereological studies was not feasible, and clinical information was 
sometimes limited. Tissue from normal controls was obtained from the Johns Hopkins Brain Resource Center and the Emory Alzheimer's Disease Research Center.

Formalin-preserved tissue was methodically sampled with regions of interest based on recent human imaging investigations, animal studies, and findings from secondary $\mathrm{CD}$. The regions sampled included the somatosensory cortex, caudate nucleus, putamen, globus pallidus, midbrain (including substantia nigra, red nucleus, INC), brainstem, cerebellar hemispheres and vermis, and deep cerebellar nuclei. Tissue was embedded in paraffin and sectioned at $10 \mu \mathrm{m}$.

\section{Genetic testing}

Genotyping was performed on unstained sections from all CD cases and controls. Brain tissue was scraped from slides and transferred to microcentrifuge tubes. DNA was extracted with the Classic ${ }^{\mathrm{TM}}$ Genomic DNA Isolation Kit (Lamda Biotech, St. Louis, MO) and examined for sequence variants in exon 5 of TOR1A and all exons and introns of THAP1 in 2 independent runs involving sections from different brain regions, with Sanger sequencing as described previously (Xiao et al., 2009; Xiao et al., 2010) .

\section{Histological procedures}

The staining battery was designed to detect inclusion bodies, in view of studies of other forms of dystonia (McNaught et al., 2004). Stains for degenerative processes were included in view of the association between $\mathrm{CD}$ and degenerative Parkinsonian disorders (Boesch et al., 2002; Papapetropoulos and Singer, 2006). Stains for inflammatory processes were included because of prior associations of focal dystonia with autoimmune diseases (Moore et al., 1986; Rajagopalan et al., 1989; Deitiker et al., 2011). Staining methods included hematoxylin/eosin (H\&E), cresyl violet, Hirano silver, and immunohistochemistry. For immunohistochemistry, sections were stained for neuronal markers (parvalbumin, calbindin, calretinin), markers for intracellular inclusions (IC2 for polyglutamine sequences, TAR DNA binding protein 43, ubiquitin), neuroglial markers (glial fibrillary acidic protein, human leukocyte antigen-DR and ionized calcium binding adapter molecule 1), and cluster of differentiation 3, a T-cell marker. Sections first were heated at $37^{\circ} \mathrm{C}$ overnight, then heated to $60^{\circ} \mathrm{C}$ for $1 \mathrm{hr}$ and deparaffinized. For antigen retrieval, sections were boiled in distilled water for $7 \mathrm{~min}$. Nonspecific binding was blocked with 5\% goat serum in phosphate-buffered saline, containing $0.4 \%$ Triton X-100 for $1 \mathrm{hr}$ at room temperature. Slides were incubated with primary antibody overnight at room temperature and then with secondary antibody for $1 \mathrm{hr}$. Sections then were incubated with streptavidin-peroxidase complex and developed for 5 min with diaminobenzidine, and counterstained with cresyl violet.

\section{Two-stage analysis}

In the first stage of the analysis, an experienced neuropathologist (C.A. Pardo) examined the first 4 brains for overt changes. This subjective assessment revealed frequent ubiquitinpositive inclusions in melanized nigral neurons and a patchy but prominent loss of cerebellar Purkinje cells. In the second stage of the study, material from the original 4 brains plus 2 additional brains that became available after the initial study were analyzed. The two main subjective findings identified in stage one were quantified and compared to age-matched controls by a microscopist blinded to phenotype. Tissue from 12 controls was investigated for the analysis of nigral inclusions, and 13 controls were studied for the Purkinje cells analysis. Quantification of the number of nigral inclusions and Purkinje cells was performed using Stereo Investigator (MicroBrightField, Inc., Williston, VT, USA). Two ubiquitinstained sections from different regions of the substantia nigra were randomly selected for 
counting intranuclear inclusions for each case. Two H\&E-stained sections from different regions of the cerebellum were randomly selected for Purkinje cell counts for each case.

\section{Statistical analyses}

To examine the association between $\mathrm{CD}$ and the number of nigral intranuclear inclusions, two statistical approaches were used. In one approach, the analysis was based on the proportion of cells with at least one inclusion. A logistic regression model was fitted to the proportion of cells with inclusions, and both age and group (CD or control) were analyzed as explanatory variables. To adjust for the correlation among neuronal cells within a given case, the Williams weighting option was used as implemented in SAS PROC LOGISTIC (SAS Institute Inc., Cary, NC, USA), which assumed an exchangeable correlation structure. The above approach had the limitation that it ignored information about the number of inclusions per cell. To use this cell-specific information, we considered an alternative approach based on the number of inclusions (ranging from 0 to 6 ) for each neuron. A loglinear regression model was fitted for the number of inclusions, and age and group were analyzed as explanatory variables. The generalized estimating equation method (Liang and Zeger, 1986) was used to adjust for intra-individual correlation among the cells.

Purkinje cell loss was investigated by examining linear Purkinje cell density measured as the number of cells $/ \mathrm{mm}$ of Purkinje cell layer. Fitted linear regression models employing the generalized estimating equation approach were used to examine the association between $C D$ and Purkinje cell density, with adjustments for age and the intra-individual correlation of Purkinje cell density measurements (Liang and Zeger, 1986). In this model, Purkinje cell density was the response variable and both age and group (CD or control) were explanatory variables. Residual plots were used to determine if there were departures from model assumptions, such as evidence of nonlinearity or non-constant variance.

A linear regression analysis using the generalized estimating equation approach also was conducted to investigate the association between the occurrence of THAP1 sequence variants and Purkinje cell density, adjusted for age and group. In all regression analyses described, two persons with ages reported as "over 80 " were assigned arbitrarily the age of 85.

\section{Results \\ Samples}

The CD cases consisted of 5 women and 1 man (Table 2). Mean age at onset was $45 \pm 10.7$ years, and mean age at death was $70.0 \pm 10.4$ years. Mean duration of $C D$ was $25 \pm 15.3$ years. Post-mortem intervals ranged from 5 to 25 hours. None of the $6 \mathrm{CD}$ cases examined had clinical histories of prolonged agonal states with hypoxia, nor histories of taking drugs known to cause neuropathological changes. In stage 2 of the study, findings from CD individuals were compared to 16 age-matched controls (average age at death of $69.5 \pm 9.8$ years, Table 2).

Although none of the CD cases had a family history of dystonia, all were examined for mutations associated with DYT1 and DYT6 dystonia. There were no c.904_906delGAG mutations or other variants in exon 5 of TOR1A. In contrast, 2 single nucleotide sequence variants in the non-coding region of THAP1 (c.71+9C $>\mathrm{A}$ and c.268-31A $>\mathrm{G})$ were identified in both cases and controls (Table 2). The intron 1 variant (c.71+9C>A) was found in $3 \mathrm{CD}$ cases. The intron 2 variant (c.268-31A $>\mathrm{G})$ was found in $2 \mathrm{CD}$ cases and 1 control. The $\mathrm{c}$. 268-31 A $>\mathrm{G}$ variant is novel, but the c.71+9C $>\mathrm{A}$ variant has been reported (Xiao et al., 2010; LeDoux et al., 2012). 


\section{Screening phase}

Tissue quality for all CD cases chosen for the final examinations showed good preservation and no signs of prolonged hypoxia before death. The most salient findings in the midbrain included focal areas of gliosis, satellitosis (accumulation of glial cells around neurons), and frequent ubiquitin-positive intranuclear inclusions in the substantia nigra (Figure 1). These small and homogeneous round inclusions resembled Marinesco bodies, a common finding in melanin-pigmented neurons in the substantia nigra pars compacta and locus ceruleus of normal aged humans (Yuen and Baxter, 1963). Findings in the cerebellum included focal areas of Bergmann gliosis, patchy loss of Purkinje cells, and torpedo bodies in the granule cell layer (Figure 2). Torpedo bodies are axonal swellings of Purkinje cells that are thought to be a non-specific result of abnormal accumulation of cellular constituents (Mann et al., 1980; Louis et al., 2009). No consistent abnormalities were seen in regions implicated in recent imaging and animal studies including the cerebral cortex, basal ganglia, INC, red nucleus or pons. Findings for each case are summarized in Table 3.

\section{Quantification phase}

Ubiquitin-positive intranuclear inclusions in the substantia nigra were quantified in $6 \mathrm{CD}$ individuals and 12 controls (Table 4). The number of melanized neurons available for counting ranged from 139 to 1393 . The number of inclusions in individual melanized neurons ranged from 0 to 6 . Among $\mathrm{CD}$ individuals, $8 \%$ of the cells counted had at least one inclusion, as compared to $11 \%$ of cells counted in the control group. The mean \pm standard deviation for the total number of inclusions indentified was 35.8 \pm 25.2 for the CD group and $63.0 \pm 81.3$ for the controls. The logistic regression analysis results indicated that neither group (Wald test: $\mathrm{W}=0.44 ; 1 \mathrm{df} ; p=0.51$ ) nor age (Wald test: $\mathrm{W}=1.41 ; 1 \mathrm{df} ; p=0.24$ ) was a significant predictor of the proportion of cells with inclusions. The estimated intraindividual correlation was $\mathrm{r}=0.06$ among the cells counted. Further analysis included an investigation of the association between number of inclusions per cell, group and age. Loglinear regression analysis based on the number of inclusions (ranging from 0 to 6) per cell failed to converge to a solution, owing to numerical difficulties. As an alternative, computationally simpler approach, a square root transformation was applied to the inclusion counts in order to stabilize their variances, and a linear regression model was fitted using the generalized estimating equation method. The results of this cell-specific regression analysis indicated that neither group (Wald test: $\mathrm{W}=0.89 ; 1 \mathrm{df} ; p=0.37$ ) nor age (Wald test: $\mathrm{W}=-0.74$; $1 \mathrm{df} ; p=0.46$ ) was a significant predictor of the number of inclusions. The quantitative study therefore failed to confirm any abnormality of nigral inclusions in the CD brains.

Main subjective findings in the cerebellum included loss of Purkinje cells, areas of focal gliosis and torpedo bodies. Due to difficulties in quantifying gliosis and the low frequency of torpedo bodies, the only variable analyzed was Purkinje cells. The linear density of Purkinje cells was measured in two separate cerebellar sections from each of $6 \mathrm{CD}$ individuals and 13 controls (Figure $3 \mathrm{~A}$ ). The $\mathrm{CD}$ group had an average linear density of $2.26 \pm 0.48$ cells $/ \mathrm{mm}$, whereas controls had an average linear density of $2.70 \pm 0.58 \mathrm{cell} / \mathrm{s} / \mathrm{mm}$. Regression analysis indicated that $\mathrm{CD}$ was significantly associated with lower linear density of Purkinje cells (Wald test: $\mathrm{W}=-2.06 ; 1 \mathrm{df} ; p<0.05$ ). The estimated intra-individual correlation was $\mathrm{r}=0.73$ for the linear density of Purkinje cell measurements. Age was not a significant predictor of Purkinje cell linear density $(p=0.72)$. Moreover, dropping age from the model did not affect the fitted regression coefficient for group, indicating that age was not a confounding variable. Residual plots did not reveal any apparent departures from model assumptions. These results confirm a lower linear density of Purkinje cells in CD brains in comparison with controls. 
Independent from patient group (CD vs controls), samples with a THAP1 sequence variant had a lower linear density of Purkinje cells $(2.14 \pm 0.54$ cells $/ \mathrm{mm})$ compared to THAP1 negative cases $(2.75 \pm 0.48$ cells $/ \mathrm{mm}$ ) as revealed by linear regression analysis (Wald test: $\mathrm{W}=-2.00 ; 1 \mathrm{df} ; p<0.05$; Figure 3B). The controls with THAP1 sequence variants (N7 and N12) fell at the lower limits of normal for linear density. The unexpected finding of THAP1 sequence variants in the control group led to a more detailed investigation of the available medical records. N7 had no neurological problems, but N12 had a history of hand tremors. The neuropathological evaluation of N12 was not consistent with Parkinson's disease, but available records were insufficient to determine if the tremors were consistent with dystonic or essential tremor.

\section{Discussion}

This study provides neuropathological findings from the largest cohort of CD patients ever evaluated. Guided by recent findings from human neuroimaging studies and animal models, it provides a more thorough and quantitatively rigorous evaluation than previously available. In the more traditional subjective phase of these studies when $4 \mathrm{CD}$ brains were available, two changes appeared salient. The CD brains appeared to have a relatively large number of Marinesco bodies in the substantia nigra. The $\mathrm{CD}$ brains also appeared to show reduced cerebellar Purkinje neurons, along with related findings of increased torpedo bodies and focal regions of gliosis. Extensive stains failed to reveal any consistent defects in the basal ganglia, cerebral cortex, red nucleus, or INC. The absence of consistent structural defects in these regions was disappointing, considering that these areas have been implicated in multiple prior studies relevant to CD (Carpenter et al., 1958; Malouin and Bedard, 1982; Fukushima, 1987; Walker et al., 1990; Neychev et al., 2011). In the second quantitative phase of these studies, the reduced number of Purkinje neurons was confirmed, but the increase in nigral inclusions was not. Although the study did not intend to address neuropathology associated with THAP1 sequence variants, an incidental finding was a significantly lower linear density of Purkinje cells among cases harboring such variants, regardless of whether they had CD or not. The results are valuable for three main reasons. First, they highlight some general weaknesses in the way that human neuropathological studies for dystonia have been conducted, and they lead to suggestions for potential solutions. Second, they question recent classifications of dystonia that propose to discriminate secondary from primary forms by the presence or absence of neuropathological correlates. Third, they highlight limitations inherent to all studies that involve attempts at clinico-pathological correlations, including dystonia.

\section{Limitations of human neuropathology}

While it may initially seem surprising that no prior study has identified the changes described in the current studies, an analysis of the prior reports reveals several explanations. One reason is that there are only 15 reported cases, with most studies including only 1-2 cases, making it difficult to appreciate subtle defects (Foerster, 1933; Grinker and Walker, 1933; Alpers and Drayer, 1937; Garcia-Albea et al., 1981; Jankovic et al., 1987). Moreover, all prior studies relied exclusively on subjective impressions of a neuropathologist, with no quantification of suspected abnormalities, eliminating the possibility of identifying subtle quantitative differences. Additionally, several of these reports included cases with clinical or neuropathological findings suggesting secondary CD (Table 1), and others combined different primary dystonias, presuming a common neuropathological substrate (Gibb et al., 1988; Zweig et al., 1988; Holton et al., 2008). By mixing different disorders in the same study, any potentially consistent defect limited to primary CD becomes difficult to discern. With a single exception (Holton et al., 2008), all prior reports were published more than two 
decades ago; and they did not include special methods such as immunohistochemistry with the power to detect specific neuropathological processes.

Perhaps the most serious shortcoming of prior studies is that many focused only on specific regions of interest. As summarized in a recent review (Neychev et al., 2011), the belief that all forms of dystonia arise from dysfunction of the basal ganglia has dominated scientific thought for decades, despite accumulating evidence that other brain regions are involved. Some of the prior autopsy studies highlighted abnormalities in the striatum and/or globus pallidus in tissue of CD individuals (Foerster, 1933; Alpers and Drayer, 1937; Holton et al., 2008). However, brain regions other than the basal ganglia were often not analyzed in detail, so it is possible that additional defects in other areas were overlooked. Furthermore, several prior studies of CD did not address the cerebellum (Alpers and Drayer, 1937; Tarlov, 1970; Zweig et al., 1986; Gibb et al., 1988; Holton et al., 2008). Among the few studies that reported a broader analysis in cases of probable primary $\mathrm{CD}$, one described patchy loss of Purkinje cells, but quantitative comparisons to controls were lacking (Garcia-Albea et al., 1981). As a result, the authors interpreted these findings as normal for age.

Wherever possible, the current study aimed to avoid the limitations of prior studies. To avoid problems associated with mixing different forms of dystonia together, we focused on cases with primary $\mathrm{CD}$. Cases of secondary $\mathrm{CD}$ were excluded. Although dystonia outside of the neck region was allowed, CD was the main clinical problem. We also employed an extensive battery of histological stains sensitive for detecting inclusion bodies, degeneration, or inflammatory processes. We also took advantage of evidence from modern human neuroimaging studies and animal studies to guide selection of brain regions. The Marinesco bodies in the substantia nigra initially were intriguing, in view of evidence that they may be more frequent in dopamine-related disorders (Beach et al., 2004), combined with evidence of dysfunction of dopamine pathways in dystonia (Perlmutter and Mink, 2004; Wichmann, 2008). The cerebellar defects also were intriguing, in view of recent studies suggesting abnormal cerebellar Purkinje neuron activity in dystonia (Pizoli et al., 2002; Neychev et al., 2008; Chen et al., 2009). As a final step, we sought to confirm subjective findings with rigorous quantitative methods. We were unable to confirm an increase in Marinesco bodies, highlighting the weakness in relying on subjective impressions. However, we were able to confirm a reduction in the linear density of cerebellar Purkinje neurons. Purkinje neurons densities in CD overlapped with those of controls (Figure 2), explaining how such a defect might be overlooked in prior studies.

After the histopathology was completed, molecular studies were conducted to identify sequence variants associated with DYT1 and DYT6 dystonia. Although none had the GAG deletion of DYT1 dystonia, 4 cases and 2 controls unexpectedly were found to harbor sequence variants in THAP1. Because the spectrum of THAP1 mutations responsible for causing DYT6 dystonia is heterogeneous and not yet fully defined, it is not clear if these variants are pathogenic (Xiao et al., 2010; LeDoux et al., 2012; Paudel et al., 2012). The c. $71+9 \mathrm{C}>\mathrm{A}$ variant was first reported by Xiao and colleagues (Xiao et al., 2010) with an allele frequency of 7/2420 in mainly adult-onset primary dystonia and 1/1200 in matched controls. Although this variant could alter splicing efficiency and the ratio of the two known THAP1 isoforms, follow-up studies (Groen et al. 2010, Lohmann et al. 2011, Kamm et al. 2011, Groen et al. 2011) have been underpowered to determine if this variant is statistically associated with risk for dystonia (LeDoux et al., 2012). The c.268-31A >G variant is novel. In comparison to previous work using DNA derived from whole blood (Xiao et al., 2010), the relatively high frequency of THAP1 variants in the post-mortem samples examined in this study suggests the possibility that THAP1 is prone to somatic mutations (Kennedy et al., 2012). Nonetheless, THAP1 sequence variants appear to be associated with significantly lower linear density of Purkinje cells regardless of the existence of $\mathrm{CD}$, a finding consistent 
with observations that Purkinje cells express the highest levels of this gene in the brain (LeDoux et al., 2012). The existence of THAP1 sequence variants in 2 controls led to questions regarding whether they should be included in the final analysis, especially since one clinically had overt tremor. However, eliminating these controls improved the strength of the association between lower Purkinje cell density and CD, because both of these controls fell at the lowest limits of the control group (Figure 3). These findings emphasize the importance of molecular diagnosis in both cases and controls.

Despite an improved study design, our study still had several shortcomings. We examined only 6 CD brains. Based on the results we obtained for Purkinje cell linear density, a power analysis indicates the need for $15 \mathrm{CD}$ cases for a confirmatory follow-up study. Because CD is so rare, obtaining this many cases could take many years without a large-scale cooperative effort. The rarity of CD and the small number of brains evaluated also creates a risk of missing subtle changes elsewhere in the brain, but were not sufficiently obvious to be detected in the screening neuropathological portion of our study. Many histological findings were not quantified, so it remains possible that significant changes exist in brain regions other than the cerebellum.

Another limitation of our study was that it involved tissue available through a public brain bank, where precise selection of matched brain regions was not feasible. Tissue selection is important, because different body regions are represented somatotopically in many brain regions, including the cerebellum. Tissue from the medial cerebellum where proximal body regions such as the neck are represented could not be compared to tissue from the hemispheres, which are more relevant for the distal limbs. It also was not possible to compare the corresponding right and left sides of the brain, which may be important for a disorder such as CD, where the head and neck are consistently turned or tilted in one direction. A related limitation was the paucity of detailed clinical information, such as the direction of head movements, which could be important for interpreting asymmetrical findings in the brain, or presence of tremor, which is associated with neuropathological findings similar to those reported here (Louis et al., 2006; Louis and Vonsattel, 2008; Shill et al., 2008; Louis et al., 2009; Louis et al., 2011).

A final limitation was the inability to include truly stereological methods for counting inclusions and cells. Truly unbiased stereological studies of human autopsy material are rarely feasible because of specific requirements including sectioning of the entire region of interest, systematic random sampling through the tissue, and particularly the requirement for random planes of section (Kristiansen and Nyengaard, 2012). Finally, despite a comprehensive battery of stains, none was sensitive for the detection of changes in the fine structure of neurons, such as dendrites. Most of these limitations are a common problem in autopsy studies and they might be solved by the establishment of a centralized brain bank, where the collection and processing of clinical information together with post-mortem brains could be standardized. Any follow-up study also would have to account for THAP1 sequence variants, and ideally incorporate new evidence regarding which of these variants may be pathogenic.

\section{Relevance for classifying the dystonias}

The results of these studies are directly relevant to efforts that classify the many different dystonias by etiology. Traditionally, primary and secondary dystonias are distinguished largely based on whether the clinical phenotype is pure or mixed with non-dystonic features. However, some investigators have suggested that the distinction also includes the occurrence of histopathogical defects (Neychev et al., 2011). For example, some authors have described primary dystonia as a "neurofunctional disorder" because of the absence of apparent neurodegeneration (Breakefield et al., 2008). Others have similarly stated that 
primary dystonia is characterized by "abnormal functioning of a structurally-normal appearing brain" (Tanabe et al., 2009). Several additional authors have implied that primary dystonias are defined in part by the absence of neuropathological abnormalities (De Carvalho Aguiar and Ozelius, 2002; Nemeth, 2002; Schwarz and Bressman, 2009).

The current studies showing a lower linear density of Purkinje neurons in the cerebellum in $\mathrm{CD}$ demonstrate that neuropathological changes may be revealed in primary dystonia when appropriate methods are applied. In fact, prior studies of human DYT1 primary generalized dystonia have shown peri-nuclear inclusions in the brainstem, although frank cell loss was not apparent (McNaught et al., 2004). Histological studies of animal models of DYT1 dystonia also have revealed subtle changes of the structure of the dendrites of cerebellar Purkinje neurons (Zhang L et al., 2011) or size of midbrain dopamine neurons (Song et al., 2012). Finally, modern human neuroimaging studies of CD have repeatedly provided evidence for microstructural defects (Neychev et al., 2011; Zoons et al., 2011). In view of these findings, it seems likely that additional neuropathological changes will be uncovered. If this is the case, then reliance on the presence or absence of neuropathological abnormalities to discriminate primary from secondary dystonia becomes increasingly problematic.

\section{Inferring causation from clinico-pathological studies}

Results from clinico-pathological studies inevitably lead to questions regarding a causal link between the clinical features and the histopathological defects. The results presented here are correlative and cannot establish a causal link between $\mathrm{CD}$ and a lower linear density of Purkine neurons. In fact, Purkinje cell loss is a non-specific finding that is associated with a variety of conditions. Purkinje cell loss is typical of a large group of disorders known as the spinocerebellar ataxias (Yang et al., 2000; Sarna and Hawkes, 2003). However, Purkinje cell loss sometimes is associated with other degenerative disorders such as Parkinson's disease (Takada et al., 1993; Wenning et al., 1996) or Alzheimer's disease (Sarna and Hawkes, 2003; Mavroudis et al., 2010). Purkinje cell loss also occurs in non-degenerative disorders including essential tremor (Louis et al., 2006; Louis and Vonsattel, 2008; Louis et al., 2011), hypoxia/ischemia (Sarna and Hawkes, 2003; Kern and Jones, 2006), traumatic brain injury (Sarna and Hawkes, 2003; Park et al., 2007), autism (Sarna and Hawkes, 2003; Kern and Jones, 2006), a variety of drugs and toxins (Sarna and Hawkes, 2003), and even normal aging (Sarna and Hawkes, 2003; Zhang C et al., 2010). Cerebellar Purkinje neurons therefore seem unusually vulnerable to many biological processes.

It is important to note that our cases had a relatively narrow age range that statistically did not contribute to Purkinje cell density, none had clinical histories of using drugs known to affect Purkinje neurons, none had evidence of another neurodegenerative disease or trauma, and tissue quality was good with no evidence of prolonged hypoxia before death. Thus, it is unlikely that Purkinje cell loss resulted from these other conditions. However, the association of Purkinje neuron loss with other disorders emphasizes that the lower linear density of Purkinje neurons found in $\mathrm{CD}$ is not specific to this disorder, and probably not responsible for causing dystonic symptoms.

The relationships between $\mathrm{CD}$ and essential tremor are important to consider. Clinically, up to two thirds of patients with CD have a tremor that resembles essential tremor (Jankovic et al., 1991; Pal et al., 2000), and recent studies have suggested that CD and essential tremor may share similar genetic substrates (Hedera et al., 2010). The neuropathology of essential tremor is similar to our findings, with subtle reductions in the linear density of Purkinje neurons, prominent torpedo bodies, and focal areas of Bergmann gliosis (Louis et al., 2006; Louis and Vonsattel, 2008; Shill et al., 2008; Louis et al., 2009; Louis et al., 2011). In view of the many relationships between $\mathrm{CD}$ and essential tremor, it is perhaps not surprising that 
they may share some similar pathological features. In essential tremor, the loss of Purkinje neurons may not cause tremor, but instead may reflect a pathological neurophysiological process involving aberrant oscillatory activity in circuits that involve the cerebellum, thalamus, and motor cortex (Raethjen and Deuschl, 2012). The reduction in the linear density of Purkinje neurons in CD may similarly reflect abnormal cerebellar physiology, although the nature of the physiological changes probably differs from essential tremor. Animal studies have suggested that abnormal bursting patterns of cerebellar Purkinje neurons may underlie dystonia, and this abnormal bursting may predispose to torpedo body formation, gliosis, and loss of these neurons (LeDoux and Lorden, 2002; Chen et al., 2009). Thus a reduction in Purkinje cell density is neither specific nor causal in CD, but may instead provide a clue to an abnormal physiology. This interpretation is consistent with recent genetic studies suggesting that $\mathrm{CD}$ may result from mutations affecting Purkinje neuron function (Xiao et al., 2012).

\section{Acknowledgments}

Human tissue for cervical dystonia cases was obtained from the NICHD Brain and Tissue Bank for Developmental Disorders at the University of Maryland in Baltimore MD, contract HHSN275200900011C, \#N01-HD-9-0011. Human tissue for controls cases was obtained from the Johns Hopkins Brain Resource Center and the Emory Alzheimer's Disease Research Center.

We thank Robert Vigorito and Ronald Zielke for their expert assistance in obtaining specimens at the NICHD Brain and Tissue Bank for Developmental Disorders. We thank Marla Gearing for assistance with obtaining control tissue from the Emory Alzheimer's Disease Research Center and the Emory NINDS Neuroscience Core Facilities. We also thank Miho Kimura and Carolina Zerrate for assistance with the histological analysis, and Elan Louis for comments on the manuscript.

\section{Abbreviations}

$\begin{array}{ll}\text { ACC } & \text { nucleus accumbens } \\ \text { AD } & \text { Alzheimer's disease } \\ \text { BG } & \text { basal ganglia } \\ \text { BL } & \text { blepharospasm } \\ \text { BS } & \text { brainstem } \\ \text { CAUD } & \text { caudate } \\ \text { CD } & \text { cervical dystonia } \\ \text { COD } & \text { complication of the disorder } \\ \text { CNF } & \text { cuneiform nucleus } \\ \text { CN III } & \text { cranial nerve III } \\ \text { CN IV } & \text { cranial nerve IV } \\ \text { CRB } & \text { cerebellum } \\ \text { CTX } & \text { cerebral cortex } \\ \text { CVD } & \text { cerebrovascular disease } \\ \text { F } & \text { female } \\ \text { FD } & \text { facial dystonia } \\ \text { FHD } & \text { focal hand dystonia } \\ \text { GP } & \text { globus pallidus }\end{array}$




\begin{tabular}{ll} 
HT & hand tremor \\
H\&E & hematoxylin/eosin \\
HIP & hippocampus \\
IC2 & anti-polyglutamine antibody \\
ID & identifier \\
INC & interstitial nucleus of Cajal \\
LC & locus ceruleus \\
M & male \\
MB & midbrain \\
MRI & magnetic resonance imaging \\
NA & not available \\
NFT & neurofibrillary tangles \\
NBM & nucleus basalis of Meynert \\
NR & not relevant \\
NT & neck tremor \\
PAG & periaqueductal gray \\
PMI & post-mortem interval \\
PPN & pedunculopontine nucleus \\
PUT & putamen \\
RF & reticular formation \\
RN & red nucleus \\
SC & spinal cord \\
SN & substantia nigra \\
STN & subthalamic nucleus \\
Sv & sequence variant \\
TDP-43 & TAR DNA binding protein 43 \\
TG & tegmentum \\
THAL & thalamus \\
UINI & ubiquitinated intranuclear inclusions \\
\hline PN &
\end{tabular}

\section{References}

Alpers BJ, Drayer CS. The organic background of some cases of spasmodic torticollis: report of case with autopsy. Am J Med Sci. 1937; 193:378-384.

Beach TG, Walker DG, Sue LI, Newell A, Adler CC, Joyce JN. Substantia nigra Marinesco bodies are associated with decreased striatal expression of dopaminergic markers. J Neuropathol Exp Neurol. 2004; 63:329-337. [PubMed: 15099023]

Boesch SM, Wenning GK, Ransmayr G, Poewe W. Dystonia in multiple system atrophy. J Neurol Neurosurg Psychiatry. 2002; 72:300-303. [PubMed: 11861684] 
Breakefield XO, Blood AJ, Li Y, Hallett M, Hanson PI, Standaert DG. The pathophysiological basis of dystonias. Nat Rev Neurosci. 2008; 9:222-234. [PubMed: 18285800]

Carpenter MB, Brittin GM, Pines J. Isolated lesions of the fastigial nuclei in the cat. J Comp Neurol. 1958; 109:65-89. [PubMed: 13563672]

Chen G, Popa LS, Wang X, Gao W, Barnes J, Hendrix CM, et al. Low-frequency oscillations in the cerebellar cortex of the tottering mouse. J Neurophysiol. 2009; 101:234-245. [PubMed: 18987121]

De Carvalho Aguiar PM, Ozelius LJ. Classification and genetics of dystonia. Lancet Neurol. 2002; 1:316-325. [PubMed: 12849429]

Defazio G. The epidemiology of primary dystonia: current evidence and perspectives. Eur J Neurol. 2010; 17(Suppl 1):9-14. [PubMed: 20590802]

Deitiker PR, Oshima M, Jankovic J, Duane DD, Aoki KR, Atassi MZ. Association of HLA Class II alleles and haplotypes with cervical dystonia: HLA DR13-DQ6 (DQB1*0604) homozygotes are at greatly increased risk of cervical dystonia in Caucasian Americans. Autoimmunity. 2011; 44:167176. [PubMed: 20843162]

Foerster O. Mobile spasm of the neck muscles and its pathological basis. J Comp Neurol. 1933; 58:725-735.

Fukushima K. The interstitial nucleus of Cajal and its role in the control of movements of head and eyes. Prog Neurobiol. 1987; 29:107-192. [PubMed: 3108957]

Garcia-Albea E, Franch O, Munoz D, Ricoy JR. Brueghel's syndrome, report of a case with postmortem studies. J Neurol Neurosurg Psychiatry. 1981; 44:437-440. [PubMed: 7264692]

Gibb WR, Lees AJ, Marsden CD. Pathological report of four patients presenting with cranial dystonias. Mov Disord. 1988; 3:211-221. [PubMed: 3193961]

Grinker RR, Walker AE. The pathology of spasmodic torticollis with a note on respiratory failure from anesthesia in chronic encephalitis. J Nerv Ment Dis. 1933; 78:630-637.

Hedera P, Phibbs FT, Fang JY, Cooper MK, Charles PD, Davis TL. Clustering of dystonia in some pedigrees with autosomal dominant essential tremor suggests the existence of a distinct subtype of essential tremor. BMC Neurol. 2010; 10:66. [PubMed: 20670416]

Hedreen JC, Zweig RM, DeLong MR, Whitehouse PJ, Price DL. Primary dystonias: a review of the pathology and suggestions for new directions of study. Adv Neurol. 1988; 50:123-132. [PubMed: 3041757]

Holton JL, Schneider SA, Ganesharajah T, Gandhi S, Strand C, Shashidharan P, et al. Neuropathology of primary adult-onset dystonia. Neurol. 2008; 70:695-699.

Jankovic J, Leder S, Warner D, Schwartz K. Cervical dystonia: clinical findings and associated movement disorders. Neurol. 1991; 41:1088-1091.

Jankovic J, Svendsen CN, Bird ED. Brain neurotransmitters in dystonia. N Engl J Med. 1987; 316:278-279. [PubMed: 2879237]

Kennedy SR, Loeb LA, Herr AJ. Somatic mutations in aging, cancer and neurodegeneration. Mech Ageing Dev. 2012; 133:118-126. [PubMed: 22079405]

Kern JK, Jones AM. Evidence of toxicity, oxidative stress, and neuronal insult in autism. J Toxicol Environ Health B Crit Rev. 2006; 9:485-499. [PubMed: 17090484]

Klier EM, Wang H, Constantin AG, Crawford JD. Midbrain control of three-dimensional head orientation. Science. 2002; 295:1314-1316. [PubMed: 11847347]

Kristiansen SL, Nyengaard JR. Digital stereology in neuropathology. APMIS. 2012; 120:327-340. [PubMed: 22429215]

LeDoux MS, Brady KA. Secondary cervical dystonia associated with structural lesions of the central nervous system. Mov Disord. 2003; 18:60-69. [PubMed: 12518301]

LeDoux MS, Lorden JF. Abnormal spontaneous and harmaline-stimulated Purkinje cell activity in the awake genetically dystonic rat. Exp Brain Res. 2002; 145:457-467. [PubMed: 12172657]

LeDoux MS, Xiao J, Rudzinska M, Bastian RW, Wszolek ZK, Van Gerpen JA, et al. Genotypephenotype correlations in THAP1 dystonia: Molecular foundations and description of new cases. Parkinsonism Relat Disord. 2012; 18:414-425. [PubMed: 22377579]

Liang KY, Zeger SL. Longitudinal data analysis using generalized linear models. Biometrika. 1986; 73:13-22.

Exp Neurol. Author manuscript; available in PMC 2014 March 01. 
Louis ED, Faust PL, Ma KJ, Yu M, Cortes E, Vonsattel JP. Torpedoes in the cerebellar vermis in essential tremor cases vs. controls. Cerebellum. 2011; 10:812-819. [PubMed: 21656041]

Louis ED, Vonsattel JP. The emerging neuropathology of essential tremor. Mov Disord. 2008; 23:174-182. [PubMed: 17999421]

Louis ED, Vonsattel JP, Honig LS, Ross GW, Lyons KE, Pahwa R. Neuropathologic findings in essential tremor. Neurol. 2006; 66:1756-1759.

Louis ED, Yi H, Erickson-Davis C, Vonsattel JP, Faust PL. Structural study of Purkinje cell axonal torpedoes in essential tremor. Neurosci Lett. 2009; 450:287-291. [PubMed: 19047012]

Malouin F, Bedard PJ. Frontal torticollis (head tilt) induced by electrolytic lesion and kainic acid injection in monkeys and cats. Exp Neurol. 1982; 78:551-560. [PubMed: 7173369]

Mann DM, Stamp JE, Yates PO, Bannister CM. The fine structure of the axonal torpedo in Purkinje cells of the human cerebellum. Neurol Res. 1980; 1:369-378. [PubMed: 6107881]

Mavroudis IA, Fotiou DF, Adipepe LF, Manani MG, Njau SD, Psaroulis D, et al. Morphological changes of the human purkinje cells and deposition of neuritic plaques and neurofibrillary tangles on the cerebellar cortex of Alzheimer's disease. Am J Alzheimers Dis Other Demen. 2010; 25:585-591. [PubMed: 20870670]

McGeer EG, McGeer PL. The dystonias. Can J Neurol Sci. 1988; 15:447-483. [PubMed: 3061633]

McNaught KS, Kapustin A, Jackson T, Jengelley TA, Jnobaptiste R, Shashidharan P, et al. Brainstem pathology in DYT1 primary torsion dystonia. Ann Neurol. 2004; 56:540-547. [PubMed: 15455404]

Moore AP, Behan PO, Behan WM. Lymphocyte subset abnormalities in patients with spasmodic torticollis. Acta Neurol Scand. 1986; 74:371-378. [PubMed: 2881425]

Nemeth AH. The genetics of primary dystonias and related disorders. Brain. 2002; 125:695-721. [PubMed: 11912106]

Neychev VK, Fan X, Mitev VI, Hess EJ, Jinnah HA. The basal ganglia and cerebellum interact in the expression of dystonic movement. Brain. 2008; 131:2499-2509. [PubMed: 18669484]

Neychev VK, Gross RE, Lehericy S, Hess EJ, Jinnah HA. The functional neuroanatomy of dystonia. Neurobiol Dis. 2011; 42:185-201. [PubMed: 21303695]

Pal PK, Samii A, Schulzer M, Mak E, Tsui JK. Head tremor in cervical dystonia. CJNS. 2000; 27:137142.

Papapetropoulos S, Singer C. Cervical dystonia as a presenting symptom of Parkinson's disease. Parkinsonism Relat Disord. 2006; 12:514-516. [PubMed: 16893668]

Park E, Ai J, Baker AJ. Cerebellar injury: clinical relevance and potential in traumatic brain injury research. Prog Brain Res. 2007; 161:327-338. [PubMed: 17618988]

Paudel R, Hardy J, Revesz T, Holton JL, Houlden H. Review: Genetics and neuropathology of primary pure dystonia. Neuropathology and applied neurobiology. 2012; 38:520-534. [PubMed: 22897341]

Perlmutter JS, Mink JW. Dysfunction of dopaminergic pathways in dystonia. Adv Neurol. 2004; 94:163-170. [PubMed: 14509670]

Pizoli CE, Jinnah HA, Billingsley ML, Hess EJ. Abnormal cerebellar signaling induces dystonia in mice. J Neurosci. 2002; 22:7825-7833. [PubMed: 12196606]

Raethjen J, Deuschl G. The oscillating central network of essential tremor. Clin Neurophysiol. 2012; 123:61-64. [PubMed: 22055842]

Rajagopalan N, Humphrey PR, Bucknall RC. Torticollis and blepharospasm in systemic lupus erythematosus. Mov Disord. 1989; 4:345-348. [PubMed: 2811894]

Sarna JR, Hawkes R. Patterned Purkinje cell death in the cerebellum. Prog Neurobiol. 2003; 70:473507. [PubMed: 14568361]

Schwarz CS, Bressman SB. Genetics and treatment of dystonia. Neurol Clin. 2009; 27:697-718. vi. [PubMed: 19555827]

Shill HA, Adler CH, Sabbagh MN, Connor DJ, Caviness JN, Hentz JG, et al. Pathologic findings in prospectively ascertained essential tremor subjects. Neurol. 2008; 70:1452-1455.

Song CH, Fan X, Exeter CJ, Hess EJ, Jinnah HA. Functional analysis of dopaminergic systems in a DYT1 knock-in mouse model of dystonia. Neurobiol Dis. 2012; 48:66-78. [PubMed: 22659308] 
Standaert DG. Update on the pathology of dystonia. Neurobiol Dis. 2011; 42:148-151. [PubMed: 21220015]

Takada M, Sugimoto T, Hattori T. MPTP neurotoxicity to cerebellar Purkinje cells in mice. Neurosci Lett. 1993; 150:49-52. [PubMed: 8469402]

Tanabe LM, Kim CE, Alagem N, Dauer WT. Primary dystonia: molecules and mechanisms. Nat Rev Neurol. 2009; 5:598-609. [PubMed: 19826400]

Tarlov E. On the problem of the pathology of spasmodic torticollis in man. J Neurol Neurosurg Psychiatry. 1970; 33:457-463. [PubMed: 5505672]

Tarsy D, Simon DK. Dystonia. N Engl J Med. 2006; 355:818-829. [PubMed: 16928997]

Walker FO, Walker JM, Matsumoto RR, Bowen WD. Torticollis, midbrain, and sigma receptors. Mov Disord. 1990; 5:265. [PubMed: 2167447]

Wenning GK, Tison F, Elliott L, Quinn NP, Daniel SE. Olivopontocerebellar pathology in multiple system atrophy. Mov Disord. 1996; 11:157-162. [PubMed: 8684385]

Wichmann T. Commentary: Dopaminergic dysfunction in DYT1 dystonia. Exp Neurol. 2008; 212:242-246. [PubMed: 18513716]

Xiao J, Bastian RW, Perlmutter JS, Racette BA, Tabbal SD, Karimi M, et al. High-throughput mutational analysis of TOR1A in primary dystonia. BMC medical genetics. 2009; 10:24. [PubMed: 19284587]

Xiao J, Uitti RJ, Zhao Y, Vemula SR, Perlmutter JS, Wszolek ZK, et al. Mutations in CIZ1 cause adult onset primary cervical dystonia. Ann Neurol. 2012

Xiao J, Zhao Y, Bastian RW, Perlmutter JS, Racette BA, Tabbal SD, et al. Novel THAP1 sequence variants in primary dystonia. Neurology. 2010; 74:229-238. [PubMed: 20083799]

Yang Q, Hashizume Y, Yoshida M, Wang Y, Goto Y, Mitsuma N, et al. Morphological Purkinje cell changes in spinocerebellar ataxia type 6. Acta Neuropathol. 2000; 100:371-376. [PubMed: 10985694]

Yuen P, Baxter DW. The morphology of Marinesco bodies (paranucleolar corpuscles) in the melaninpigmented nuclei of the brain-stem. J Neurol Neurosurg Psychiatry. 1963; 26:178-183. [PubMed: 14002893]

Zhang C, Zhu Q, Hua T. Aging of cerebellar Purkinje cells. Cell Tissue Res. 2010; 341:341-347. [PubMed: 20652318]

Zhang L, Yokoi F, Jin YH, DeAndrade MP, Hashimoto K, Standaert DG, et al. Altered dendritic morphology of Purkinje cells in DYT1 $\triangle$ GAG knock-in and purkinje cell-specific DYT1 conditional knockout mice. PLoS One. 2011; 6:e18357. [PubMed: 21479250]

Zoons E, Booij J, Nederveen AJ, Dijk JM, Tijssen MA. Structural, functional and molecular imaging of the brain in primary focal dystonia--a review. Neuroimage. 2011; 56:1011-1020. [PubMed: 21349339]

Zweig RM, Hedreen JC, Jankel WR, Casanova MF, Whitehouse PJ, Price DL. Pathology in brainstem regions of individuals with primary dystonia. Neurol. 1988; 38:702-706.

Zweig RM, Jankel WR, Whitehouse PJ, Casanova MF, Hedreen JC, Price DL. Brainstem pathology in dystonia. Neurol. 1986; 36:74-75.

Exp Neurol. Author manuscript; available in PMC 2014 March 01. 


\section{Highlights}

- Subjects with cervical dystonia had a lower density of cerebellar Purkinje cells.

- Subjects with THAP1 variants had a lower density of cerebellar Purkinje cells.

- No consistent abnormalities were identified in the basal ganglia, or other regions. 


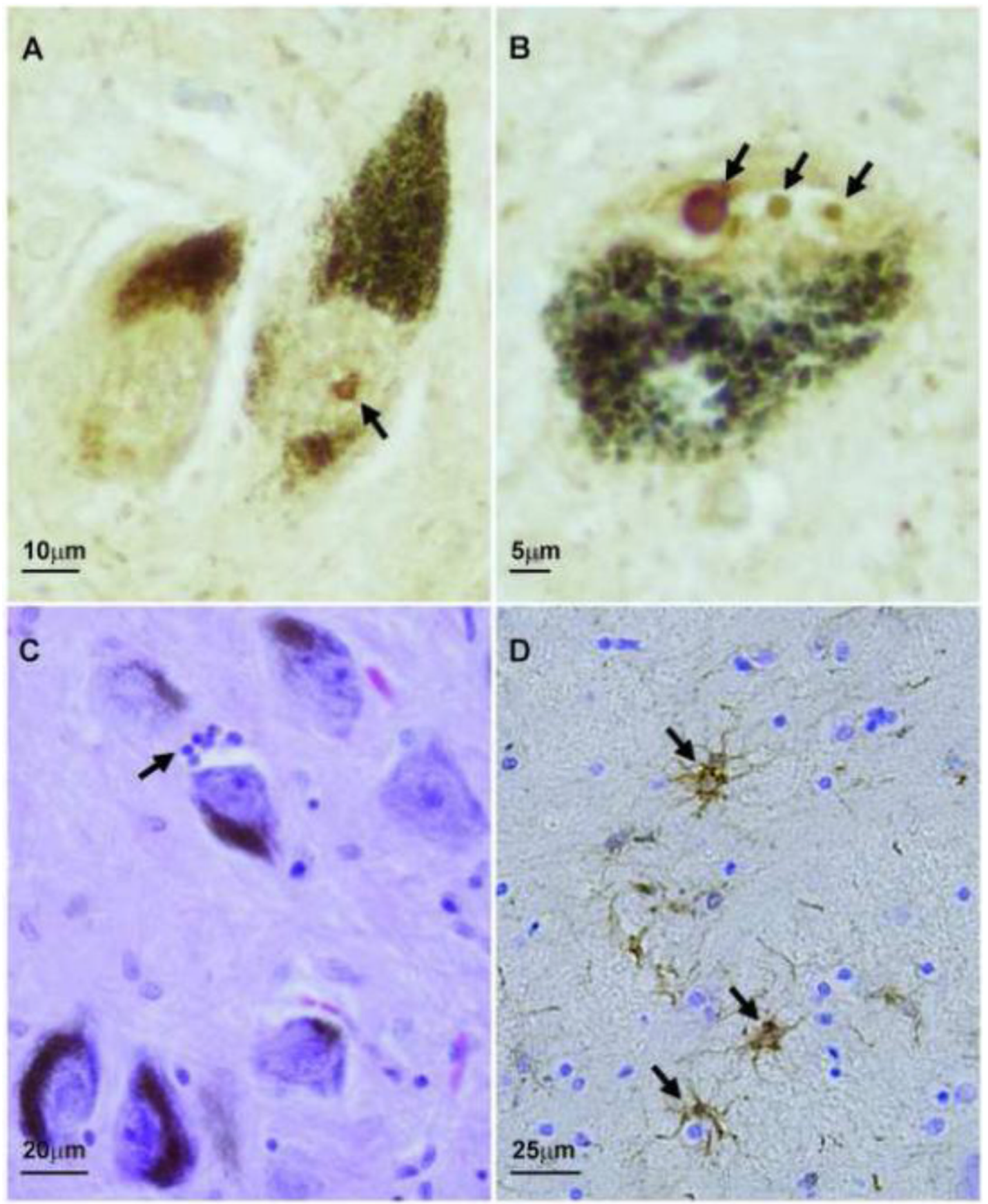

Figure 1.

Histopathology in the midbrain. Panels A-B show typical ubiquitin-positive inclusions in the substantia nigra (Marinesco bodies). Nigral neurons with one or multiple inclusions were observed (black arrows). Panel C shows an example of satellitosis (arrow) around a dopaminergic neuron in the substantia nigra. Panel D shows increased number and activation of astrocytes (gliosis, arrows) in a midbrain section of a cervical dystonia case. Panels A-B: ubiquitin immunostaining; Panel C: hematoxylin and eosin; Panel D: glial fibrillary acidic protein. 

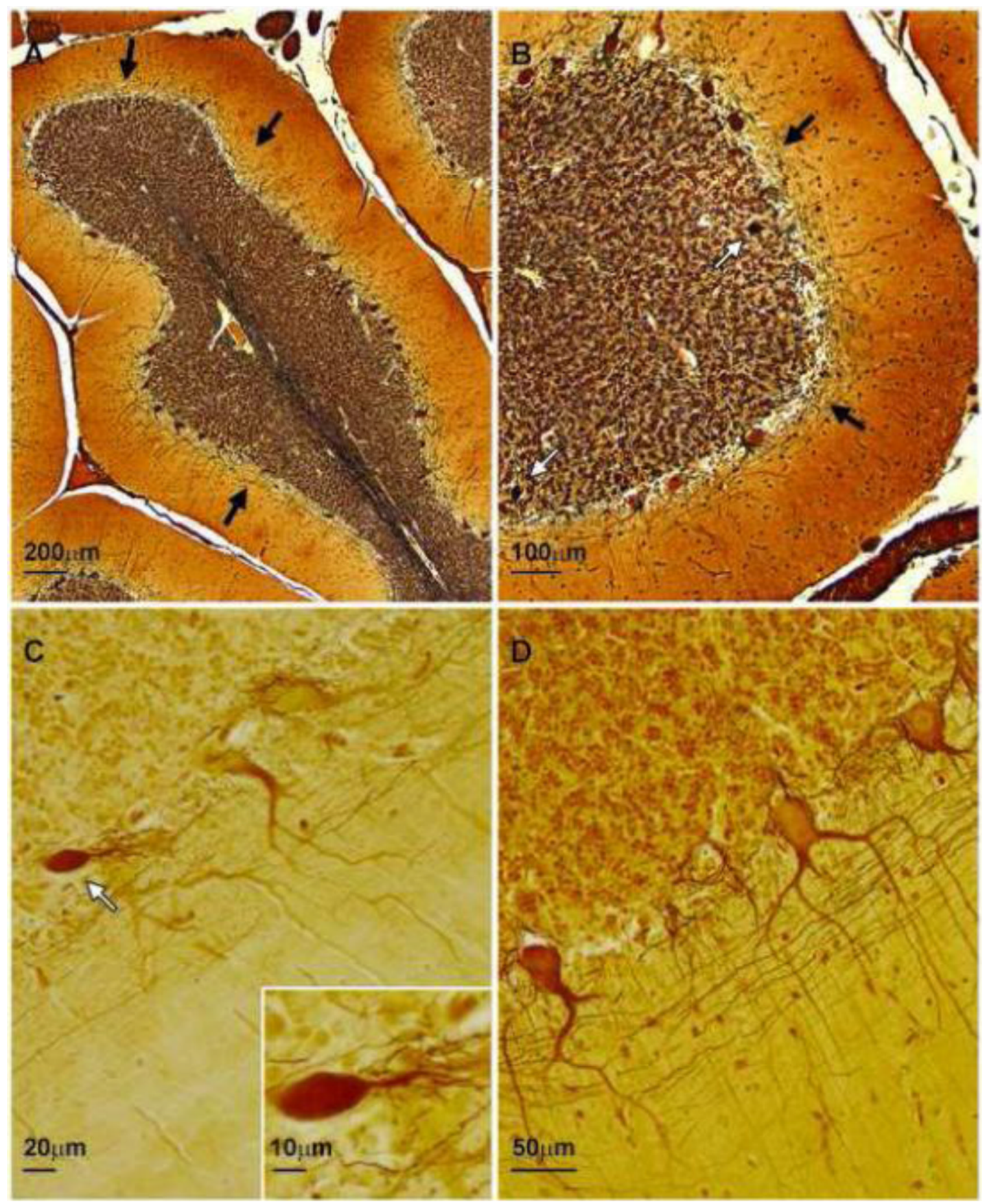

Figure 2.

Histopathology in the cerebellum. Panels A-B shows areas with patchy loss of Purkinje cells, as indicated by the black arrows. Torpedo bodies (white arrows) can be identified in Panels B-C. Panel D shows a typical Purkinje cell layer with morphologically normal cell bodies. Panels A-D: silver impregnation. 


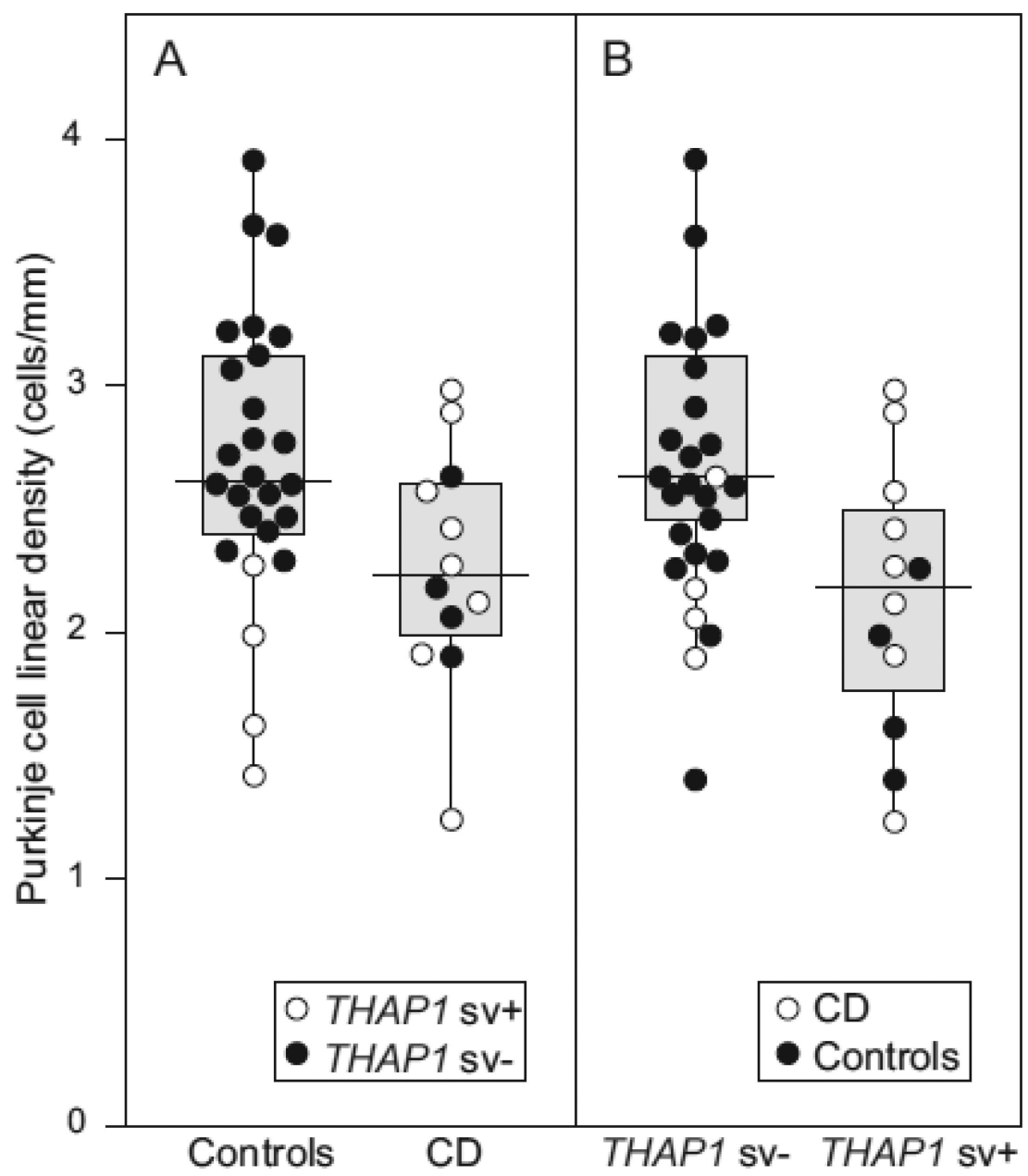

Figure 3.

Box and whisker plot comparing Purkinje cell linear density in 6 cervical dystonia (CD) cases and 13 controls. In this type of plot, the upper and lower limits of the box show the upper and lower quartiles of the data, with the horizontal line in between showing the median. The whiskers show the entire data range, and circles depict each data point. Two independent sections for each subject were analyzed, and all 12 points for the CD group and 26 for the controls are shown. Regression analysis indicated that CD was significantly associated with lower density of Purkinje cells at $\mathrm{p}<0.05$ (A). Regression analysis also revealed that cases with a THAP1 sequence variant ( $T H A P 1 \mathrm{sv}+$ ) had a significantly lower linear density of Purkinje cells compared to THAP1 negative cases at $\mathrm{p}<0.05$ (THAP1 sv-) (B). In A, open and closed circles represent the data for $T H A P 1$ positive and negative cases within each group. In $\mathrm{B}$, open and closed circles represent the data for $\mathrm{CD}$ and controls within each $T H A P 1$ group. 


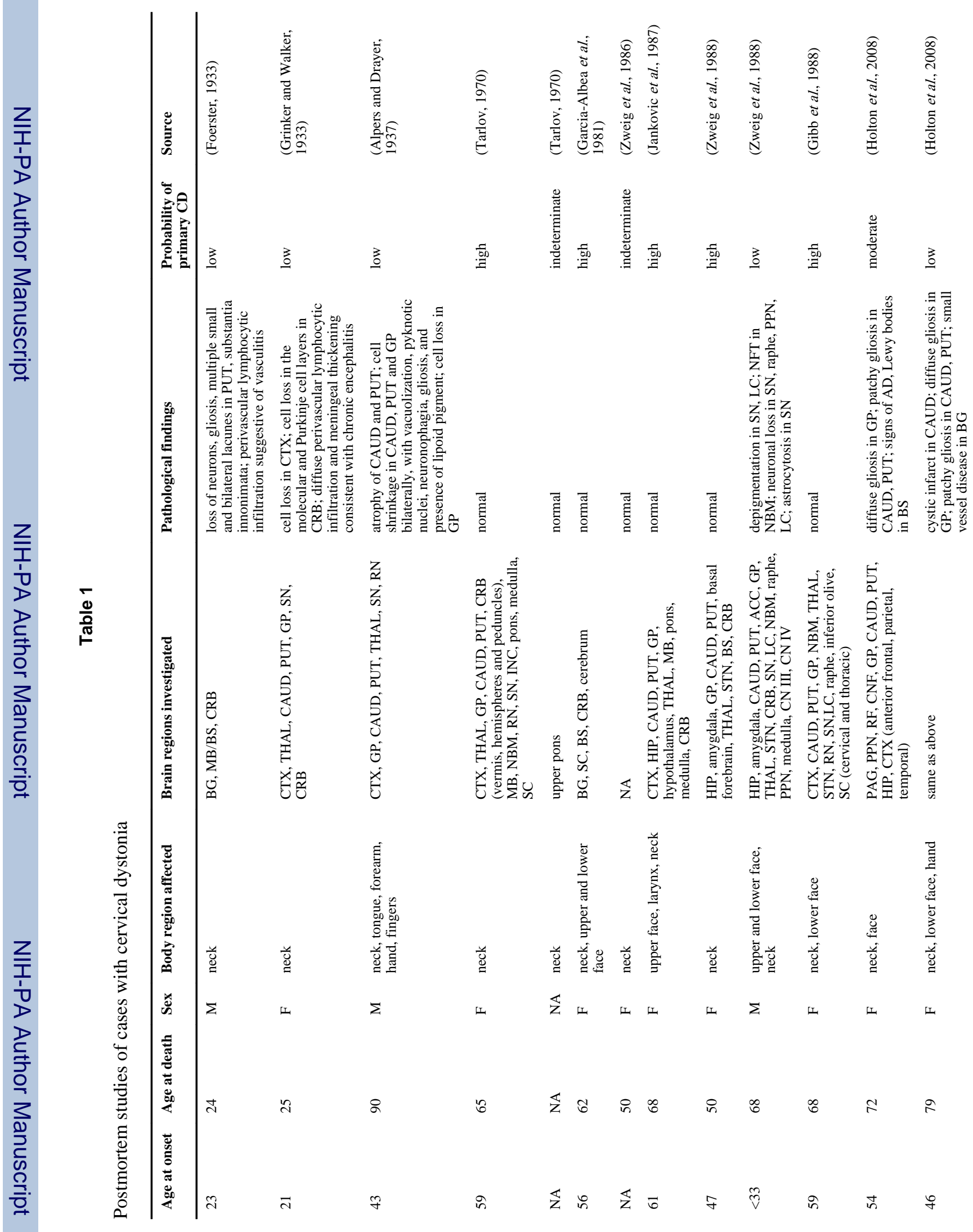




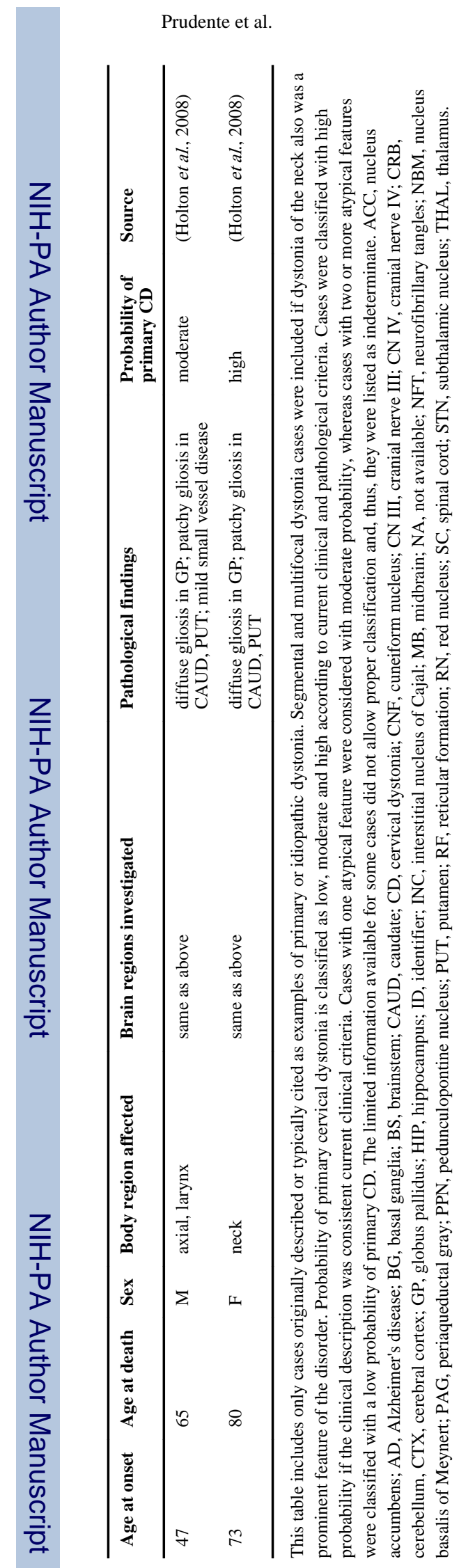

Exp Neurol. Author manuscript; available in PMC 2014 March 01. 


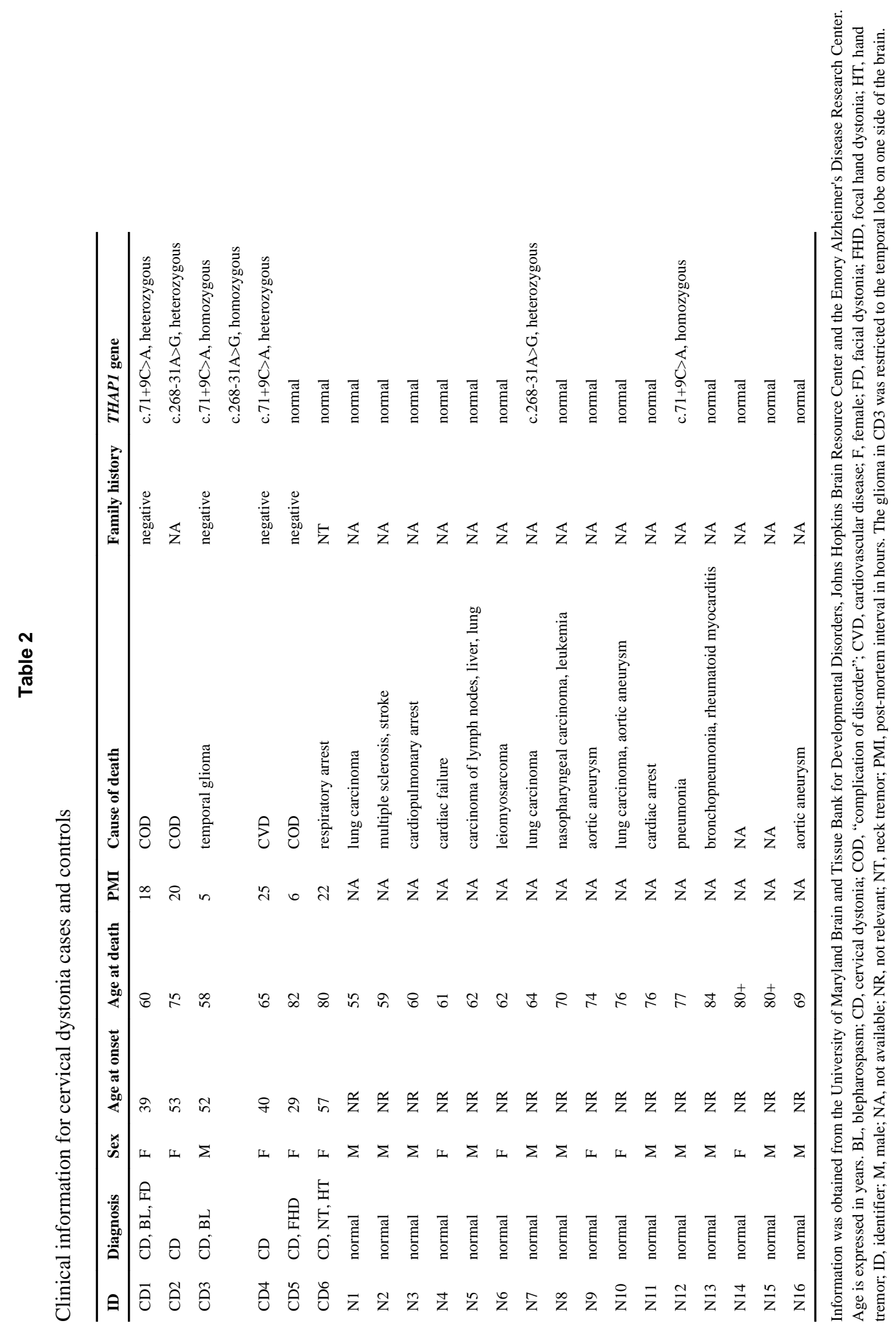

Exp Neurol. Author manuscript; available in PMC 2014 March 01. 


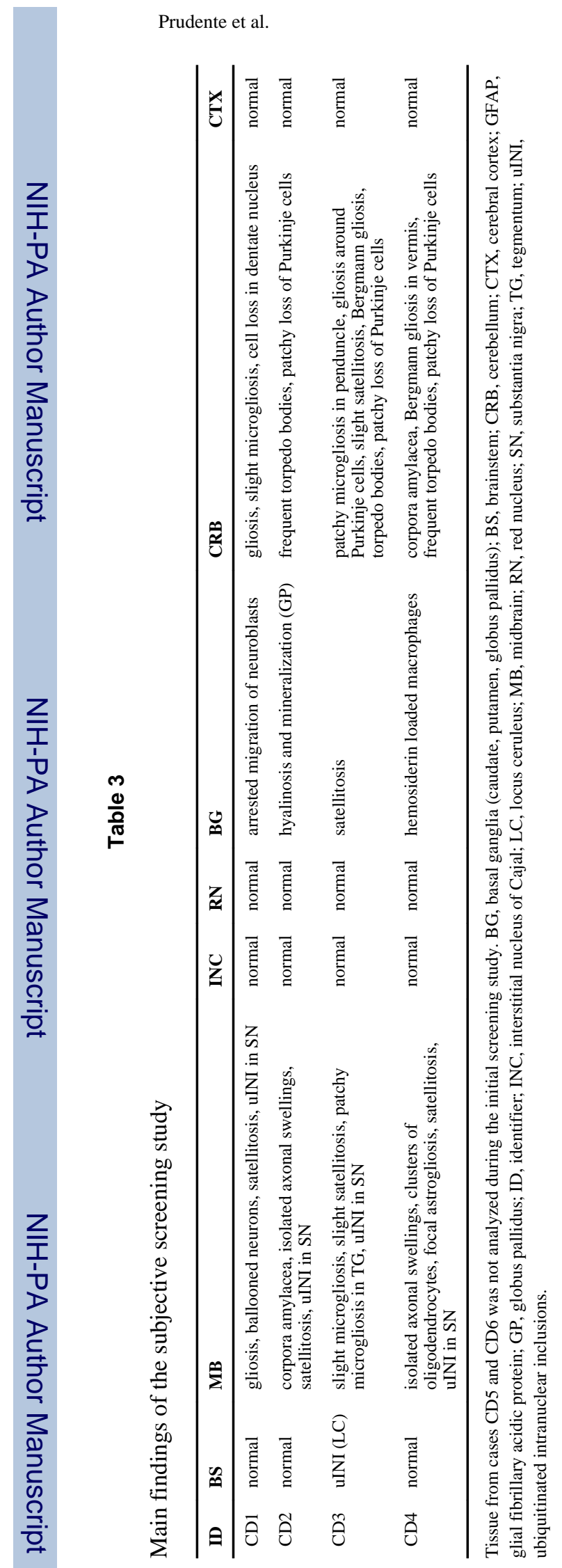

Exp Neurol. Author manuscript; available in PMC 2014 March 01. 


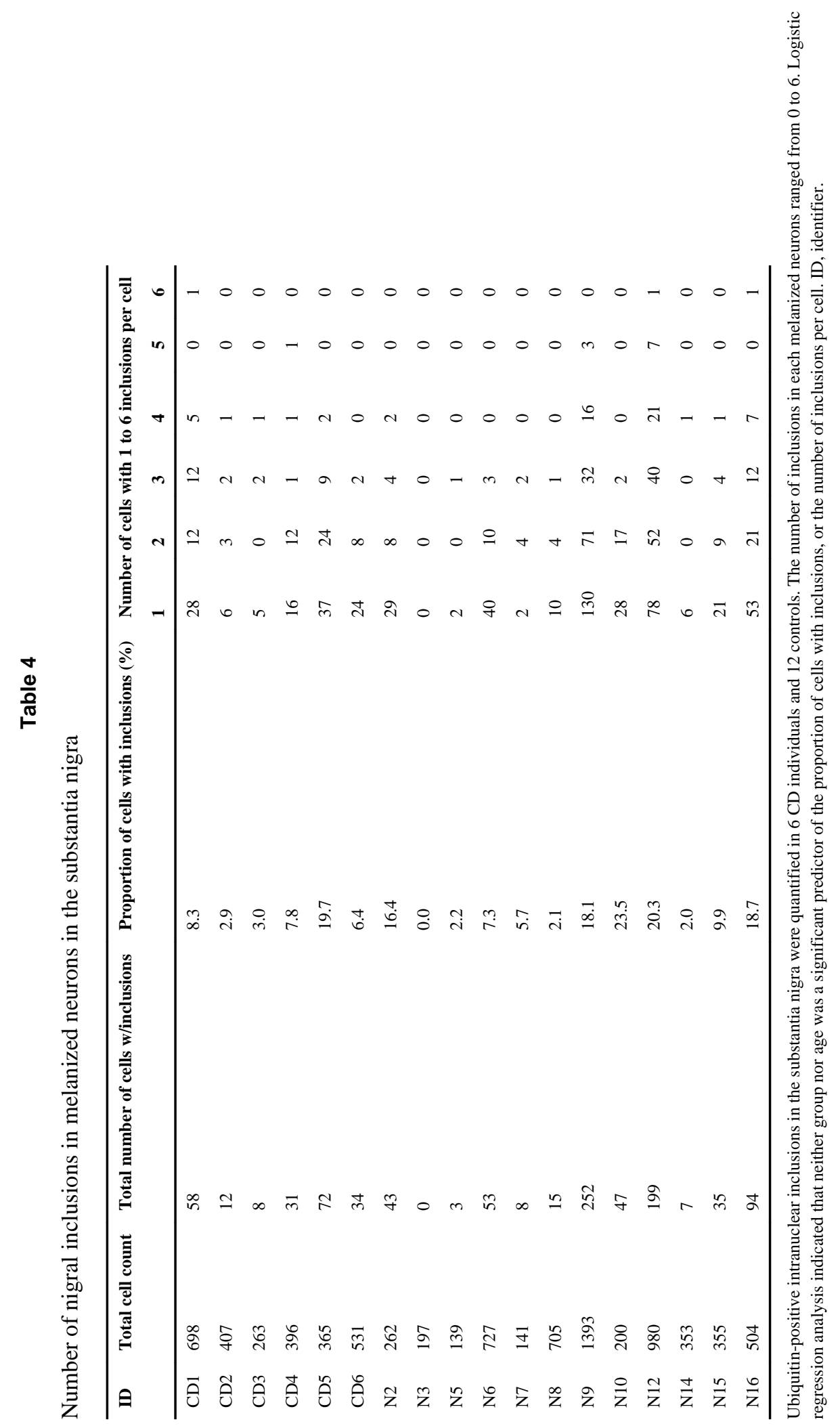

Exp Neurol. Author manuscript; available in PMC 2014 March 01. 